\title{
In the Classroom
}

\section{Who is the Real Owner? Or How a Simple Pepsi-Cola Story Can Help Students Build Critical Thinking Skills}

\section{Tatiana Galetcaia and Loreena Thiessen}

Besides language competence, international students must develop a systematic approach to processing information and follow up with co-construction of the knowledge acquired. Critical thinking is a crucial principle commonly required in North American universities for evaluating academic texts. This practice may present certain difficulties for English-as-an-additional-language (EAL) students, as they may be influenced by cultural norms accepted in the academic environment of their home country or by dissimilar approaches to evaluating academic texts. This article discusses our classroom experience with assisting EAL students, predominantly from China and Saudi Arabia, in developing critical thinking skills; however, the operational model offered may also be useful with students from other cultural backgrounds.

Au-delà de la compétence langagière, les étudiants internationaux doivent développer une approche systématique au traitement de l'information et poursuivre avec une démarche de coconstruction des connaissances acquises. La pensée critique est un principe décisif qui est généralement exigé dans les universités en Amérique du Nord lors de l'évaluation des textes académiques. Cette pratique peut présenter certaines difficultés pour les étudiants pour qui l'anglais est une langue additionnelle étant donné qu'ils pourraient être influencés par des normes culturelles acceptées dans un milieu académique dans leur pays d'origine ou par des approches dissimilaires à l'évaluation de textes académiques. Cet article évoque notre expérience en classe qui a consisté à assister les étudiants pour qui l'anglais est une langue additionnelle, surtout ceux de Chine et d'Arabie saoudite, à développer des habiletés de pensée critique. Toutefois, le modèle opérationnel offert peut également s'avérer utile auprès d'étudiants d'autres origines culturelles.

You must unlearn what you have learned. (Yoda in The Empire Strikes Back, cited in Early \& Ang, 2003) 


\section{Teaching Critical Analysis Skills and Problems Encountered}

In view of what is generally required of university students and of the difficulties that international students often face, the Academic English Program for University and College Entrance (AEPUCE) at the University of Manitoba offers workshops on university skills-development featuring elaboration of learning techniques including critical analysis of academic texts written in English.

Although we thought that the objectives of our text-analysis workshops were quite self-explanatory, we quickly observed that for many students, our focus on critical thinking was quite foreign. The difficulties became especially obvious when students were assigned to critique their first text. Initially, we taught critical thinking explicitly. We demonstrated how critical thinking worked by explaining in chart and diagram form patterns of academic thought and delineating specific aspects as parts or steps in critical analysis. From such theory, we expected the students to move directly into analyzing the academic texts that we placed before them.

It quickly became evident that the term critical thinking was a concept not clearly understood by our students. They could not tackle the task because it mystified them. They were baffled by the terminology used in explaining the theory, and they did not understand what was required of them. Most frequently, students summarized the content of an article without offering analytical comments. Clearly we had to find another way of teaching critical thinking so as to evoke expression of critical consciousness by our students. In search of a new operational model to facilitate that process, we turned to the potential reasons behind the obstacles we had observed.

Reflection on our first experience of teaching critical thinking and many discussions with the students suggested two possible causes that may have impeded the expected success: (a) students' misconceptions or certain myths related to what critiquing means; (b) our choice of explicit instruction.

\section{The Premise of Myths}

Extensive communication with our students, along with many classroom observations of how they dealt with academic texts in the interdisciplinary activities of our program, made it possible for us to infer the premise of three myths that seemed to create a need for us to develop a more effective introduction to critical thinking. These myths appeared to be central to the students' understanding of and approach to learning, and they were observed in explanatory excuses when students faced new, difficult, or complex tasks. Among the questions we asked the students both in class and through interviews were: How do you understand critical thinking? What do you have to do with the text when asked to critically evaluate it? What do you need to do in order to produce a critical analysis of an academic text? Students' answers and opinions consistently centered on three principal beliefs that illustrated their 
concepts of what critical analysis was and how they could perform it. We referred to these assumptions as myths because they mirrored the essential inaccuracy of the students' conceptions of both the task and the method to achieve it.

The myths were as follows.

1. A perception that to critique a publication meant to find the defect that would ultimately represent an article's information or view as valueless, as opposed to seeking an analytical examination or deconstruction of the facts, ideas, intent, or method as presented by the writer.

2. Apparently based on the above, a belief and assertion that because they were not experts, students were not qualified to have an academic opinion or lacked the ability to assess or intelligently comment on a publication. Rather than progress with their own examination of the text, the students developed a heavy dependence on the teacher's interpretation.

3. The third myth, relating to a working hard formula for academic success, illustrated the belief that efforts to work hard or harder-a kind of generalized quantitative application of increased energy-would produce the required result. Rather than focusing on effective strategies for improved performance, our students often adopted the phrase work harder as a mantra that would somehow produce the desired outcome.

Becoming aware of these mythical beliefs initiated our search for an alternative approach to teaching these skills based on our work with the students.

\section{Critical Thinking: Cultural Thinking?}

The literature suggests that despite being a central feature of academic work in most Western institutions, critical thinking occupies an indefinite space in the conceptual inventory of education. As a feature of general human learning, critical thinking seems to range from simple evaluative operations based on elementary likes or dislikes, through to complex, deep insights involving diverse patterns of analytical thought. Such a range of complexity defies any clear-cut definition of its meaning, which made the concept difficult to explain to our students. Direct pedagogical instruction could be problematic, because the process of critical thinking entails strategies hardly subject to formal or explicit teaching. In addition, it appears that the operational strategies of text-critiquing may vary across individuals in terms of the speed, intensity, and sequence of cognitive acts.

Another significant feature of critical thinking is that it may be viewed as a culturally embedded concept, with preferred evaluative approaches particular to specific groups (Atkinson, 1997; Hofstede \& Hofstede, 2005). As culture consists of patterned ways of thinking, feeling, and reacting to various situations and actions (Kluckholn, cited in Early \& Ang, 2003), it can strongly influence habitual ways of dealing with new information. Thus it 
can be argued that thought and knowledge are culturally rooted, shaped, and negotiated as coherent social practices (Hinkel, 1999). Critical thinking, especially in the form encountered in Western educational systems (Atkinson, 1997), is a common component in North American schooling. However, there can be a gap between how individual students imagine the critical thinking process and how teachers see it, and this clash of understandings may be most salient when students are international arrivals and when teachers tend to promote a Western approach to problem-solving based on individualistic initiative. On the simplest level, difficulties may well arise when students are asked to practice something that they have not previously practiced or even imagined.

Although we were aware that in fact university-level critical thinking tasks can be demanding for all students who are new to the institution, including those entering with a Canadian educational background, our teaching experience suggested that the academic skill of critical thinking could be especially challenging for some international students who seemed reluctant to express and substantiate critical evaluations. Other modes of socialization can include variations in preferred communication style and in approaches to individual and collective achievement (Peterson, 2004), which seemed directly to influence our students' perceptions in their treatment of the texts assigned to them for critical review. Critical thinking may be viewed as a highly variable pursuit of text evaluation, entailing patterns of thought influenced by diverse factors including a group's predominant cultural perceptions and practices.

Remembering that human behavior is mostly learned (Miller \& Dollard, 1979), and considering what might give rise to the difficulties that our students seemed to experience as they struggled through the target task, we turned to the principles of the specific modes of socialization presumably affecting our students' approaches to critical analysis. Most of the students in the AEPUCE program came to study in Canada from China; when we asked these cohorts to comment on how comfortable they felt when practicing the critique of academic texts in a reflective paragraph, a number of common perceptions stood out-despite some variations-that reflected two basic principles of traditional Chinese philosophy: the role of authority and the importance of face or honor for individuals, in line with observations by Chuang (2007) and Kennedy (2002). The key virtue for understanding the value of both is respect. Chinese conventional mores have been said to prescribe respect for authority as well as "self-respect as a precondition of all moral action" (Roetz, 1993, p. 161). In the context of our discussion, authority would be embodied in the scholarly source of information to which students refer in their academic assignments, whether represented by a single author or a group of authors. Such authoritative figures may resemble the category of shi, or educated intellectuals, stemming from the noble ranks of past tradi- 
tional Chinese society; according to Confucian mores, the highly valued scholar (shi) is skilled in certain arts and other practical fields and embodies the spirit of the intellectual, moral, and courageous person who contributes to the establishment of social norms (Roetz). We formed the impression that the prevalent unwillingness to voice personal judgment on an academic text may have been based on our students' belief that a scholar's opinion was highly respected and should not be criticized. In order to express criticism, one should be an even better expert. Because our students did not consider themselves experts, they could not imagine themselves critiquing an authoritative document without undermining their own reputation or self-respect. The view seemed to be that the reader must be authoritative enough to challenge the author of the text, and because this was not believed to be the case, no student wished to lose face; there seemed to be a perceived obligation to act in the appropriate role: "Let the ruler be ruler, the subject be subject, the father be father, the son be son" (Lunyu, cited in Roetz, p. 49). Or in our context, Let the scholar be a scholar, the student just a student. This may be what stood behind the second powerful myth: that students are in no position to critique experts, expressed so often by students when they were not comfortable with critiquing academic articles. Thus the questions that we asked about this myth helped us to see not only why our students did not feel at ease when critiquing texts, but also why they experienced difficulties in understanding the concept of plagiarism as understood by Canadian academics. By all accounts, many members of these student cohorts considered the original texts "already very good," with the most common comment along those lines being "that the author's expression is better than what I want to say" (Qian \& Krugly-Smolska, 2008, p. 77). This seems to coincide with the myth to which our students referred most often as an explanation for not performing the critical evaluation of a text.

A similar tendency to perceive arguments in English academic texts from a culturally influenced perspective was also often observed among students in Saudi Arabian cohorts, the second-largest group in our program. Perhaps, as noted by Al-Jibouri, Williams, and Holes (cited by Connor, 1996), because they expected a repetition of the main theme to be central to the argument in argumentative discussions, as commonly appears in classical Arabic texts, these students frequently tended to reduce systematic analysis of the whole text to attention to only one aspect of the argument. In discussions of this nature, counterargument would often be replaced by stories or parables echoing those in the Koran, whereas the argument itself might be directly addressed little or not at all. In this connection, one of our students explained, "It is better to express your opinion by one similar story from the well-known text which is the strongest authority by itself than to use dozens of words the opponent might disagree with." Obviously such an approach is different from the typical Western pattern of critiquing based on direct 
references to the author's standpoint and substantiated by evidence from related research. Thus evidence and data to support the argument were commonly missing in critiques by our Saudi Arabian students, reflecting an argumentative style in which such elements were unnecessary, which resonated closely with Johnstone's (1986) comparison between Middle-Eastern and Western argumentative preferences.

Analyzing the tendencies of preferred approaches to composing academic texts as described above, we attempted (a) to identify common difficulties arising from the critiquing practices that these students might have encountered in their home academic environment so as to develop a more welcoming operational model to assist them; and (b) to become more aware of culturally shaped transferences from previous experiences that international students might bring to their effort to master critiquing conventions in the new conceptual framework at their present educational institution. Our goal was to suggest to students how they could succeed with the demands of the new setting not simply by working harder, but by working differently.

\section{How Did the Pepsi-Cola Story Help to Undo the Myths? Application of a Cognitive Apprenticeship Model}

Notwithstanding the far-from-self-evident nature of critical thinking as understood in the courses our students would be required to take, as well as students' misperceptions about it, such challenges can be overcome. Encouraging students to participate in analytical classroom discussions can become simpler if the assignment takes the form of an engaging activity (see Appendix): this insight is always important because no student group is likely to find the practice of critical thinking easy to assimilate, but it may become especially crucial when international students are the target audience. Insights from the literature and our observations suggest that critical thinking cannot simply be taught in the most literal sense (Atkinson, 1997; Early \& Ang, 2003; Hinkel, 1999; Holliday, Hyde, \& Kullman; 2004). To be understood it has to be performed. The patterns of critiquing in the student's home academic environment might be not consistent with the patterns preferred in Canadian universities. If critical thinking reflects a hardly teachable pursuit and a culturally shaped practice that cannot be shifted easily if at all, the model of instruction should be aimed at practice rather than at theory. To build more confidence in practicing critical thinking, such cohorts need hands-on activities that shift the focus from the obscurity and complexity of the unfamiliar task to the interest and excitement of the role that students may be offered. Students must first relate the text to their personal experience or senses in order to feel somehow connected to its plot, and only later apply the algorithm of analyzing the situation. 
The shortest way to learn critical thinking is to use critical thinking skills: "the head remembers what it does," that is, what learners do determines what is learned (Halpern, 2003). In order to engage the students immediately, we gave them an appealing and readable text. The arresting plot of the story "You can be the judge: Who is the real owner?" (Folse \& Ivone, 2002) where the Pepsi-Cola Company's $\$ 1,000,000$ prize was found by one person, but probably belonged to her co-worker, appealed to the instantaneous attention of readers. The text had no difficult vocabulary, and we did not give instructions on patterns of thought or any theory of critique. The story itself was the hook; its relevance captured our students' interest. They were instantly involved in considering and weighing the facts and in attempting to understand the situation: two people claimed the prize; two sides of the conflict had to be judged. Who might be the real owner? Everyone could be the judge as each of us could apply our personal code of understood justice to this situation. The students spontaneously related to the possible reality of facing a similar dilemma. We did not tell the students that what they were doing was engaging in the basics of a formal critique; they simply read the story to understand the events and to consider the aspects it presented. They were relieved of the stresses brought about by focusing not only on vocabulary, but also on theory and patterns. The story itself caused them to consider the facts, analyze the situation, and arrive at a conclusion.

The real success was that as a result, we could demystify misconceptions about who could be an expert, because with such a text it could be anyone. The students immediately felt more confident in the task of evaluating the facts and the situation as presented in the reading. By reversing the approach of our instruction, we realized that teaching students the theory of how to critique a text could not come before the experience of actually analyzing the information in a text, which in effect was entirely another strategy. To a large extent, many students needed this opportunity to rethink much of what they might have learned before. As Hofstede and Hofstede (2005) suggested, patterns of thought, feeling, and potential action are learned throughout one's lifetime, and

much of it has been acquired in early childhood, because at that time a person is most susceptible to learning and assimilating. As soon as certain patterns of thinking, feeling and acting have established themselves within a person's mind, he or she must unlearn these before being able to learn something different, and unlearning is more difficult than learning for the first time. (pp. 2-3)

Evaluation of the ordinary information coming from a simple story, not bogged down by academic guidelines or theoretical terminology, made reconsideration of the previously attained pattern less problematic. 
The Pepsi-Cola story had the advantage of facilitating access to the perception that to criticize or critique does not necessarily mean to only to find defects in the text, and so it facilitated an understanding that critiquing could mean considering the merits and demerits of alternative perspectives on the text, problem, or situation and judging accordingly. This immediately widened the purpose and scope of the target activity beyond the myth that critiquing always means finding fault.

By placing workshop participants in the position of capable judges, we deconstructed the false premise that only an officially sanctioned expert had the right to evaluate another expert's text, which had been a stumbling-block for many of our students.

Finally, through a teaching sequence that began with applying the strategies of analysis such as identifying the core of the problem, separating the conflicting sides, and comparing and weighing the arguments and evidence on each side, we exemplified a more meaningful approach to what it meant to work effectively rather than just hard. The direct and practical analysis of such a story had the merit of highlighting in concrete terms the possibility and legitimacy of methodically evaluating the content of a text. In the workshop evaluation questionnaire, most of our students, regardless of their cultural background, indicated that the new approach had a positive effect on their understanding of critical thinking. This opened the possibility for the students to move toward evaluating academic texts. By the time they were offered a more scholarly text to critique, they were much less puzzled by the challenge of determining what stance to take when reading about currently problematic issues in such areas as computer science or marketing, for example. Equipped with a not-too-explicitly theorized but still efficient paradigm of the steps to take, namely, break the whole picture into pieces, compare their value, and synthesize them on a new level, students had the opportunity to create for themselves a tool that was potentially applicable across academic disciplines. And employing an interactive format to discuss their judgments in small groups made this task less challenging than if it had been done individually.

Interestingly, what we attempted to do in our workshop is consistent with the basic concept of cognitive apprenticeship introduced by a number of authors (Collins, Brown, \& Newman, 1989; Collins, Brown, \& Holum, 1991; Hill \& Resnick, 1995), in accordance with the view that "all significant human activity is highly situated in real-world contexts-and that complex cognitive skills are therefore ultimately learned in high-context, inherently motivating situations in which the skills themselves are organically bound up with the activity being learned" (Atkinson, 1999, p. 87). Echoing characteristics of the traditional professional apprenticeship, and focusing on a practical goal rather than on the theory of the process itself, this learningthrough-guidance experience (Collins et al., 1989) fits the model of building 
a skill without going into the details of the preliminary theory, which might complicate understanding the task. This model encourages students to dive into the targeted activity without prior explicit instruction, which could overemphasize the expertise of the teacher. To summarize, the features of the model of cognitive apprenticeship or situated learning include:

1. A focus on the goal rather than the process: Students are given a task, and by actually doing it, they come to a better understanding of how to achieve it. Novice and expert performances in these circumstances are seen as parts of a cooperative mutual problem-solving activity. This approach is called abstract replay by Collins et al., as reflecting repeated attempts "to focus students' observations and comparisons directly on the determining features of both their own and an expert's performance" (p. 458).

2. Intensive work in small groups, structured as collective problemsolving: Semi-independent activity of this nature motivates students to learn how to articulate their judgments or solutions through argumentation, which facilitates development of independent verbal thinking. The cognitive side, the understanding of situations, and the operative side, and the use of language to address the situation (Burke, 1989) influence the development of both the analysis itself and the rhetoric chosen to embody it.

3. Increasing complexity of assigned tasks with the advancement of the skills or the sequence of activities for students (Chaiklin \& Lave, 1993; Lave \& Wenger, 1991).

4. Gradual reduction of the expert advisor's role to monitoring and assessing students' performance.

Introduced a few decades ago, the universal character of this model still remains applicable to the modeling of critical thinking patterns for EAL learners, particularly at the introductory stage of instruction. It would be not realistic to claim that the proposed approach would work equally well for every student in a given class. Nor can the approach be applied with equal success for the critique of any randomly chosen text beause of genre-specific complexities. However, once thoroughly practiced, the steps of critical analysis modeled above need not be taught anew every time: in general terms, they will be accessed when dealing with each new text, which satisfies the main purpose of the workshop. Specific applications of these skills can be further polished in other ways once students understand the broad concept of how critiquing works.

\section{From Thinking Uncritically to Critical Thinking}

It is worth repeating that academic-style critical thinking is a difficult skill that has the potential to be daunting and mystifying for all students, not only those with international educational backgrounds. Nevertheless, perhaps 
especially with EAL students, teachers should be wary of supposing that learners will automatically analyze an academic text as Western educators expect. To address this challenge, teachers may offer students situational practice by presenting a text that reports a real circumstance to which learners can more easily relate. Where appropriate, this can help learners to step off a path that may be prescribed by habitual modes of socialization, which can interfere with accomplishing an unfamiliar new task. Taking for granted the unquestionable validity of a published text, as opposed to thinking critically about it, may cost students a high price by disconnecting them from the conventions of the new classroom context. Simply informing students that their preferred approach will not be successful in the new academic milieu is not enough. Practical application of the strategies for teaching critical thinking described above can be a way for teachers to present what is hardly teachable in direct terms and for students to explore questions that teachers cannot readily answer explicitly. With the help of these strategies, students can eventually learn how to challenge solutions proposed in published sources.

Thus the roles of expert and student can be subtly transformed (Collins et al., 1991). This opens the way for students to value free access to diverse methods of understanding and solving problems. Synthetic by nature, the task becomes the goal itself through its own performance. By breaking the conventional barrier between teachers as experts and students as experts-tobe, the proposed approach worked most effectively at the initial stage of learning critical analysis. Paraphrasing the Confucian maxim, it let our students be not only students, but also critical thinkers.

\section{The Authors}

Tatiana Galetcaia (MA Hons in applied linguistics, Certificate in TESL and MEd from University of Manitoba) has taught EFL/ESL in Europe and Canada for more than 20 years. She teaches academic writing for the Academic English Program for University and College Entrance (AEPUCE). Her research interests include psycholinguistic aspects of language-learning and development of research skills in international students.

Loreena Thiessen has a BA in English and German literature and certification in education from the University of Manitoba. She has taught English in various centers across Canada and is currently an instructor in the Academic English Program for University and College at the University of Manitoba. Her interests are in the thinking patterns and development and cultural adaptation of international students.

\section{References}

Atkinson, D. (1997). A critical approach to critical thinking in TESOL. TESOL Quarterly, 31, 71-94.

Burke, K. (1989). On symbols and society. Chicago, IL: University of Chicago Press.

Collins, A., Brown, J.S., \& Holum, A. (1991). Cognitive apprenticeship: Making thinking visible. American Educator, 15(3), 6-11, 38-46. 
Collins, A., Brown, J.S., \& Newman, S.E. (1989). Cognitive apprenticeship: Teaching the crafts of reading, writing, and mathematics. In L.B. Resnick (Ed.), Knowing, learning, and instruction: Essays in honor of Robert Glaser (pp. 453-494). Hillsdale, NJ: Erlbaum.

Chaiklin, S., \& Lave, J. (Eds.). (1993). Understanding practice: Perspectives on activity and context. Cambridge, UK: University of Cambridge Press.

Chuang, S.-F. (2007). The influence of Confucian philosophy on adults' preference for learning: A comparison of Confucian adult learners and non-Confucian adult learners. Unpublished doctoral dissertation, Louisiana State University. Retrieved June 27, 2010, from: http:/ /etd.lsu.edu/docs/available/etd-11012007-210852/unrestricted/Chuang_dis.pdf

Connor, U. (1996). Contrastive rhetoric: Cross-cultural aspects of second-language writing. Cambridge, UK: Cambridge University Press.

Early, P.C., \& Ang, S. (2003). Cultural intelligence: Individual interaction across cultures. Stanford, CA: Stanford University Press.

Folse, K., \& Ivone, J. (2002). More discussion starters: Activities for building speaking fluency. Ann Arbor, MI: University of Michigan Press.

Halpern, D.F. (2003). Thought and knowledge: An introduction to critical thinking. Mahwah, NJ: Erlbaum.

Hill, C.A., \& Resnick, L. (1995). Creating opportunities for apprenticeship in writing. In J. Petraglia (Ed.), Reconceiving writing, rethinking writing instruction (pp. 145-158). Mahwah, NJ: Erlbaum.

Hinkel, E. (Ed.). (1999). Culture in second language teaching and learning. New York: Cambridge University Press.

Hofstede, G., \& Hofstede, G.J. (2005). Cultures and organizations: Software of the mind. New York: McGraw Hill.

Holliday, A., Hyde, M., \& Kullman, J. (2004). Intercultural communication: An advanced resource book. New York: Routledge.

Johnstone, B. (1986). Arguments with Khomeini: Rhetorical situation and persuasive style in cross-cultural perspective. Text, 6(1), 171-187.

Kennedy, P. (2002). Learning cultures and learning styles: Myth-Understandings about adult (Hong Kong) Chinese learners. International Journal of Lifelong Education, 21, 430-445.

Lave, J., \& Wenger, E. (1991). Situated learning: Legitimate peripheral participation. New York: Cambridge University Press.

Miller, N., \& Dollard, J. (1979). Social learning and imitation. New Haven, NJ: Yale University Press.

Peterson, B. (2004). Cultural intelligence: A guide to working with people from other cultures. Yarmouth, CT: Intercultural Press.

Qian, J., \& Krugly-Smolska, E. (2008). Chinese graduate students' experiences with writing a literature review. TESL Canada Journal, 26(1), 68-86.

Roetz, H. (1993). Confucian ethics of the axial age: A reconstruction under the aspect of the breakthrough toward postconventional thinking. Albany, NY: SUNY Press.

\section{Appendix}

Workshop Format (1 hour 30 minutes, with a 20 minute break in between)

I. Pepsi-Cola story introduction (20 minutes)

1. Read individually

2. Discuss in small groups of 2-3 students; focus on

- What happened? Is the situation fair?

- Who owned the Pepsi bottle?

- You are the judge-make a ruling; give reasons.

- Compare judgments within the group. 


\section{Large-group discussion (30 minutes)}

Groups provide their judgments; They may use a poster format to outline the reasons; in case the judgments vary within a group, members summarize each perspective. The teacher (or an assigned student) summarizes the shared/contrasting points on the board, dividing them into columns according to the arguments in favour or against each side in the conflict, or according to aspects of the problem.

III. Follow-up summary of what has been done (30 minutes)

The students are asked to retrospectively break down the steps in their analysis the text situation. The teacher may list their answers on the board. Here are typical steps to identify:

- read to understand

- consider the two sides' claims

- compare the weak and strong arguments brought up by each side

- compare the validity of the evidence on each side

- evaluate facts/evidence;

- make a judgment based on the analysis

- clearly articulate the judgment and its substantiation

\section{Conclusion (10 minutes)}

1. The teacher explains to the students that what they have done reflects the basic pattern of critical thinking, which can be applied to analyze the situation / events/facts of a text.

2. The teacher may be willing to emphasise that it can be applied not only to evaluate the situation or event presented in an article, but also to evaluate the genre,language, or personal position of the author.

3. Teacher answers questions if any.

At the next workshop, students are offered readings that reflect a more academic context. In our practice, we offered articles on problematic issues in technology, medical science, and marketing. 